\title{
L3-L4 Intervertebral Space
}

National Cancer Institute

\section{Source}

National Cancer Institute. L3-L4 Intervertebral Space. NCI Thesaurus. Code C112328.

The space between the L3 and L4 vertebrae. 